UPGRADE OF AGS RF CAVITIES FOR INCREASED BEAM LOADING

BOOSTER TECHNICAL NOTE

NO. 171

M. METH and A. ZALTSMAN

JUNE 26, 1990

ALTERNATING GRADIENT SYNCHROTRON DEPARTMENT BROOKHAVEN NATIONAL LABORATORY

UPTON, NEW YORK 11973 


\title{
UPGRADE OF AGS RF CAVITIES FOR INCREASED BEAM LOADING
}

\author{
M. METH and A. ZALTSMAN
}

\section{INTRODLCTION}

The AGS RF System must be upgraded to accommodate an increase in beam loading. The system has two major facets. One is the power amplifier; the second is the cavity. This note addresses the problems associated with the cavity.

Increased beam loading due to the injection of a bunched beam from the booster into the AGS has two aspects. During the accelerating phase, steady state beam loading imposes a limit on the drive (or output) resistance of the amplifier, the Robinson resistance. The injection of a bunched beam induces a transient response in the cavities. This transient response manifests itself as a phase delay and amplitude modulation of the gap voltage, and is dependent on the product of the gap capacitance and gap voltage.

\section{TRANSIENT RESPONSE}

The transient response has been analyzed ${ }^{1,2}$. Each injected bunch induces a phase delay in the RI: gap voltage. The delay is given by

$$
\operatorname{SIN}^{-1} N \frac{\Delta Q}{C V}
$$

where

$$
\begin{aligned}
& \Delta \mathrm{Q}=\text { charge/bunch } \\
& \mathrm{C}=\text { cavity (station) capacitance } \\
& \mathrm{V}=\text { cavity peak voltage } \\
& \mathrm{N}=\text { numerical, depending on charge distribution of the bunch }
\end{aligned}
$$

For an impulse $\mathrm{N}=1 / 2$, for a half-wave sinusoid $\mathrm{N}=\pi / 8$, for a rectangular distribution $\mathrm{N}=$ $1 / \pi$. Limiting the induced phase shift to $30^{\circ}$ requires that

$$
\mathrm{CV}>\Delta \mathrm{Q} \text {. }
$$

Design parameters of the AGS cavity are:

$\Delta \mathrm{Q}: \quad$ based on $6 \times 10^{13}$ protons per pulse, with a $50 \%$ safety factor $\Delta \mathrm{Q}=1.2 \times 10^{-6} \mathrm{coul} / \mathrm{bunch}$.

C: : the equivalent capacitance of 4 gaps in series. Initially we believed that the gap capacitance was in the range of $300-330 \mu \mu \mathrm{F}$. Subsequent measure- 
ments indicate that the capacitance is $400-410$ $\mu \mu \mathrm{F} /$ gap or $100 \mu \mu \mathrm{F} /$ cavity.

$\mathrm{V}: \quad$ the peak accelerating voltage. With injection at full voltage $\mathrm{V}=40 \mathrm{KV} /$ cavity.

Thus the CV product is $4 \mu$ coul.

Injection consists of the sequential injection of 3 bunches from the booster, for an injection of $3.6 \mu$ coul/Booster pulse. The duration of the transient produced by each pulse depends on the cavity quality factor $Q_{1}$. For the transient to decay in one RF cycle $Q_{0}$ must be less than 2. The cavity, loaded by the amplifier output resistance has a $Q_{0}$ greater than 15. Thus the sequential injection of the three Booster pulses is equivalent to a transient disturbance produced by a $\Delta Q$ of $3.6 \mu$ coul. The CV product of $4 \mu$ coul is marginal and should be increased to approximately $8 \mu$ coul.

\section{UPGRADE}

The increase of cavity capacitance and voltage are not independent of each other and is limited by the Q-loss phenomenon, and ferrite dissipation. Q-loss ${ }^{3.4}$ is a time-dependent magnetic phenomena. For a constant input power the output voltage is characterized by a period of constant output followed by a decrease of output voltage. The output voltage can be held constant by increasing the drive following the on set of Q-loss. A properly functioning AGC loop can hold the output voltage constant over its linear range. During the high loss period the output voltage appears noisy. Oscillograms depicting Q-loss are included and described within the Appendix. In the references cited and in the older literature this phenomena is called highloss effect.

The minimum voltage at which Q-loss develops was measured as a function of gap capacitance and is given in Table 1 . Measurements leading to Table I were made with the AGC loxp open.

Table 1. On Set of Q-Loss

$$
\mathrm{F}=4.5 \mathrm{MHz}
$$

\begin{tabular}{|c|c|}
\hline $\begin{array}{c}\text { Gap Capacitance } \\
\mu \mu(\mathbf{F})\end{array}$ & $\begin{array}{c}\text { On Set of Q-Loss } \\
(\mathbf{K v})\end{array}$ \\
\hline 400 & 14 \\
\hline 500 & 12 \\
\hline 700 & 11 \\
\hline 800 & 7 \\
\hline 1,000 & 6.5 \\
\hline
\end{tabular}


As the value of gap capacitance is increased, the stored energy and associated ferrite dissipation also increase.

In addition, the upgrade must provide for cavity operation over a frequency range from 1.7 $\mathrm{MHz}$ to 4.5 $\mathrm{MHz}$. The lower limit is based on a RHIC operational requirement. Based on the existing gap capacitance of $400 \mu \mu \mathrm{F}$, the capacitance must increase to at least $610 \mu \mu \mathrm{F}$.

Choosing $700 \mu \mu \mathrm{F}$ as the gap capacitance and $10 \mathrm{Kv}$ as the gap voltage yields a CV product of $7 \mu \mathrm{F}$. The ferrite bias is limited to $1100 \mathrm{~A}$.

The ferrite tuning current was measured and is given in Figure 1. The CW dissipation for a gap voltage of $10 \mathrm{KV}$ was maasured as a fumction of frequency and is given in Figure 2.

Additional measurements were obtained for the AGS test cavity and are included in the Appendix.

\section{$\underline{\text { PERFORMANCE }}$}

With an added capacitance of $300 \mu \mu \mathrm{F} /$ gap (including a 100 to $150 \mu \mu \mathrm{F}$ contribution from the power amplifier) and a gap voltage of $10 \mathrm{KV}$ the following additional parameters are projected for the test cavity.

$$
\begin{aligned}
& V=40 \mathrm{KV} \\
& C=17.5 \mu \mu \mathrm{F} \\
& C V \text { Product }=7 \mu \mathrm{F} \\
& \Delta Q=3.6 \mu \mathrm{F} \\
& \text { Ferrite } \mathrm{CW} \text { Dissipation }=65 \mathrm{KW} \text {, or } 251 \mathrm{mw} / \mathrm{cc}
\end{aligned}
$$

Ferrite Shunt Resistance $=12.3 \mathrm{~K} \Omega$

Amplifier Output Resistance $=6.4 \mathrm{~K} \Omega$

Based on class AB operation of the EIMAC $4 C \mathrm{M} 300,000$ and an external 1:1 transtormer:

$$
\begin{array}{ll}
\text { Oupu Resistance } & =4.2 \mathrm{Ks} \\
\text { Robinson Resistance } & =6.35 \mathrm{~K} \Omega \\
\text { Peak Beam Power } & =125 \mathrm{KW} \\
Q_{0} \text { of Cavity } & =19
\end{array}
$$




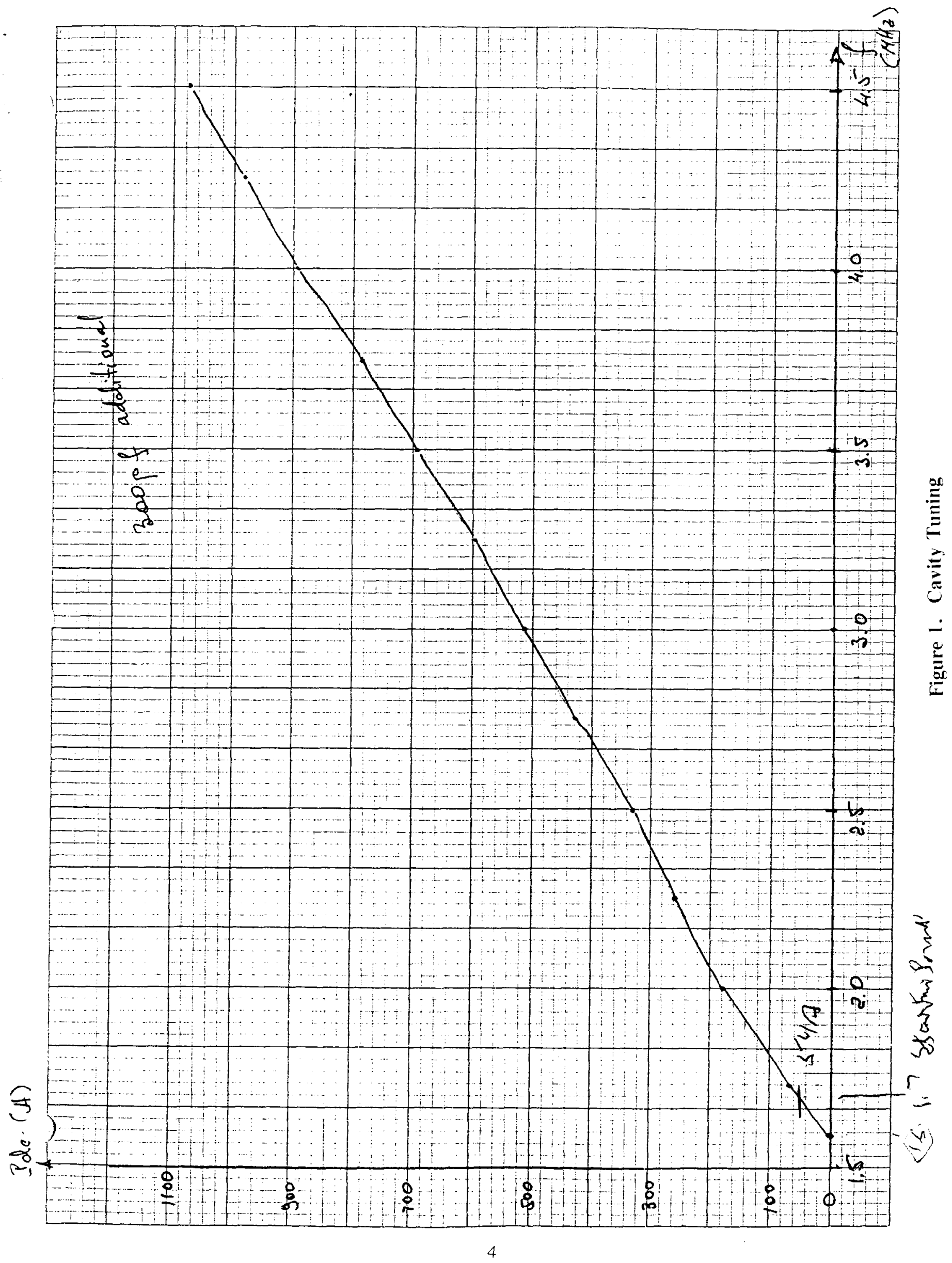




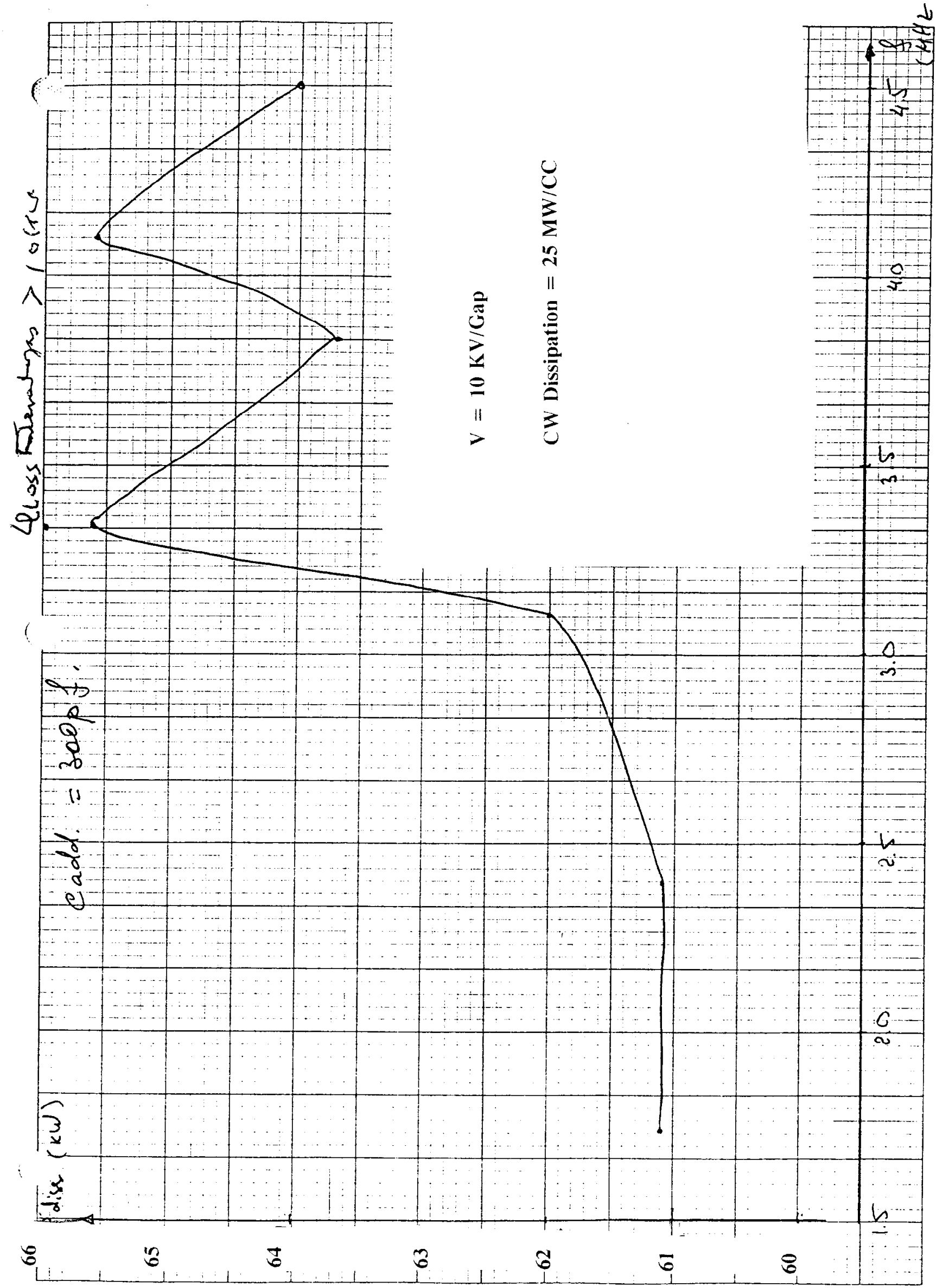




\section{REFERENCES:}

1. Meth, M. and Ratti, A.; Time Domain Beam Loading Studies of the Booster and AGS. Proceedings of the 1985 IEEE Particle Accelerator Conference, March 20-23, 1985, Chicago, IL., p168.

2. Meth, M. and Plotkin, M.; Preliminary Design of RF Power Amplifier for Upgraded AGS. Booster Technical Note \#126, August 18, 1988.

3. Kerns, Q.A. and Sandberg, B.R.; The Ferrite Teting Program at NAL, IEEE Trans. Nucl. Sci., NS-18; 244, 1971.

4. Griffins, J.E. and Nicolls, G., A Review of Some Dynamic Loss Properties of N1-Zn Accelerators RF Systems Ferrite, IEEE Trans. Nucl. Sci., NS-26, 3, June 1979. 


\begin{abstract}
APPENDIX
The tuning curves for additional gap capacitance of $620 \mu \mu \mathrm{F}, 720 \mu \mu \mathrm{F}$ and 925 are included and given in Figure A-1.

Oscillograms depicting Q-loss are given in Figure A-2. Measurements were made with $300 \mu \mu \mathrm{F}$ of capacitance added to each gap $(\mathrm{C}=700 \mu \mu \mathrm{F} / \mathrm{gap})$ and driven from a $4.5 \mathrm{MHz}$ power source. A 1000:1 voltage probe was employed, such that the vertical sensitivity is 5 $\mathrm{KV} / \mathrm{cm}$. In Figure A-2 (A), the cavity drive is adjusted for an output of $10 \mathrm{KV}$-peak, the AGC loop is open and the response is free of Q-loss. In Figure A-2 (B), the drive is adjusted for an output of $12 \mathrm{KV}$, the AGC loop is open and Q-loss is present. Note the noise during the highloss phase. In Figure A-2 (C), the AGC loop is closed and adjusted for an output of $12 \mathrm{KV}$. Note the constant output voltage level but the manifestation of noise during the high-loss phase.
\end{abstract}




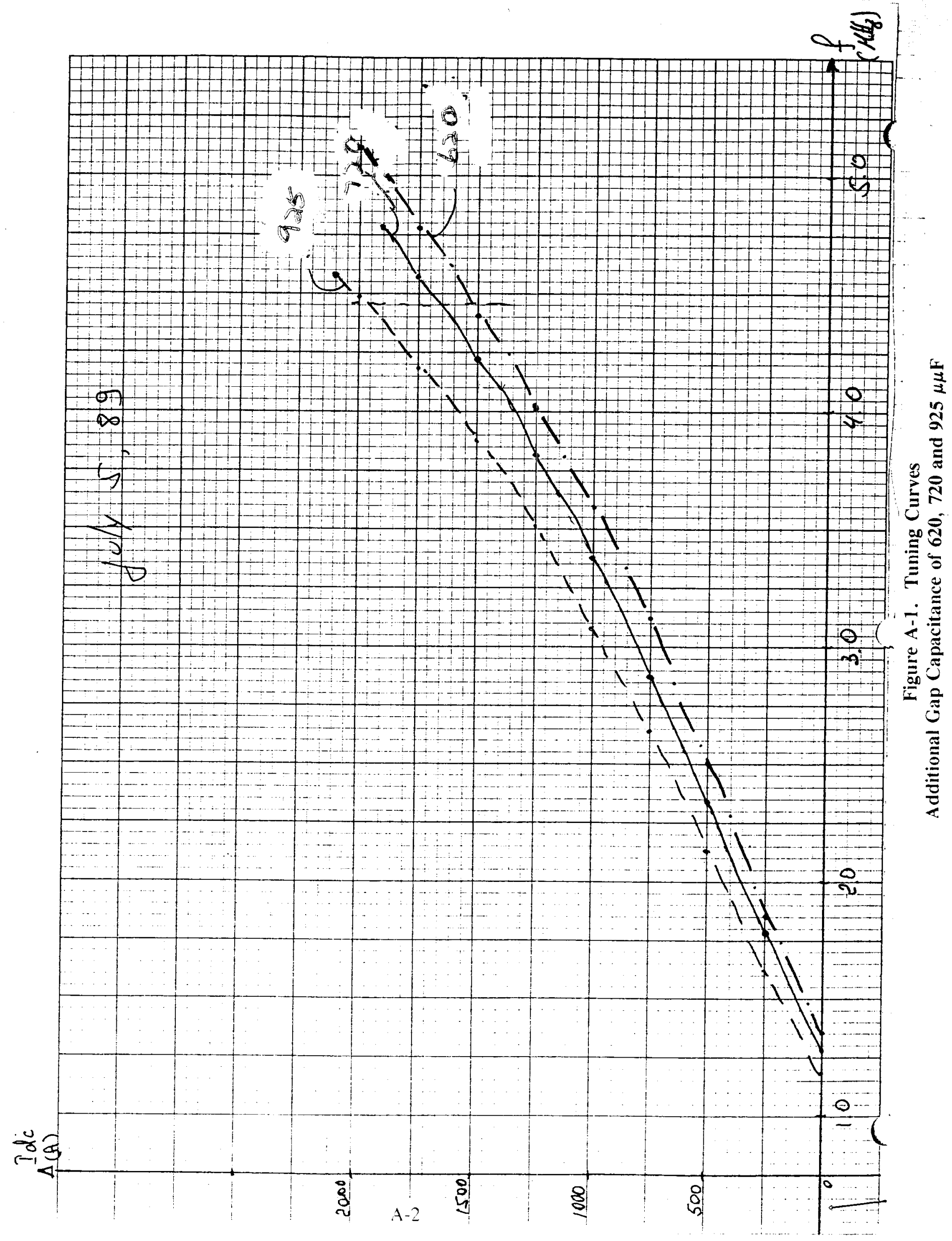




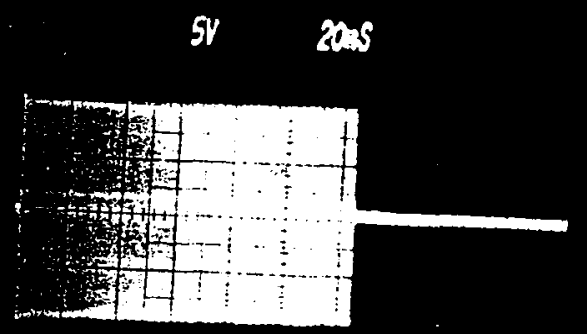

$+5 \%$

sots
Fig. A-1(A)

AGC Loop Open $\mathrm{V}=10 \mathrm{KV}$

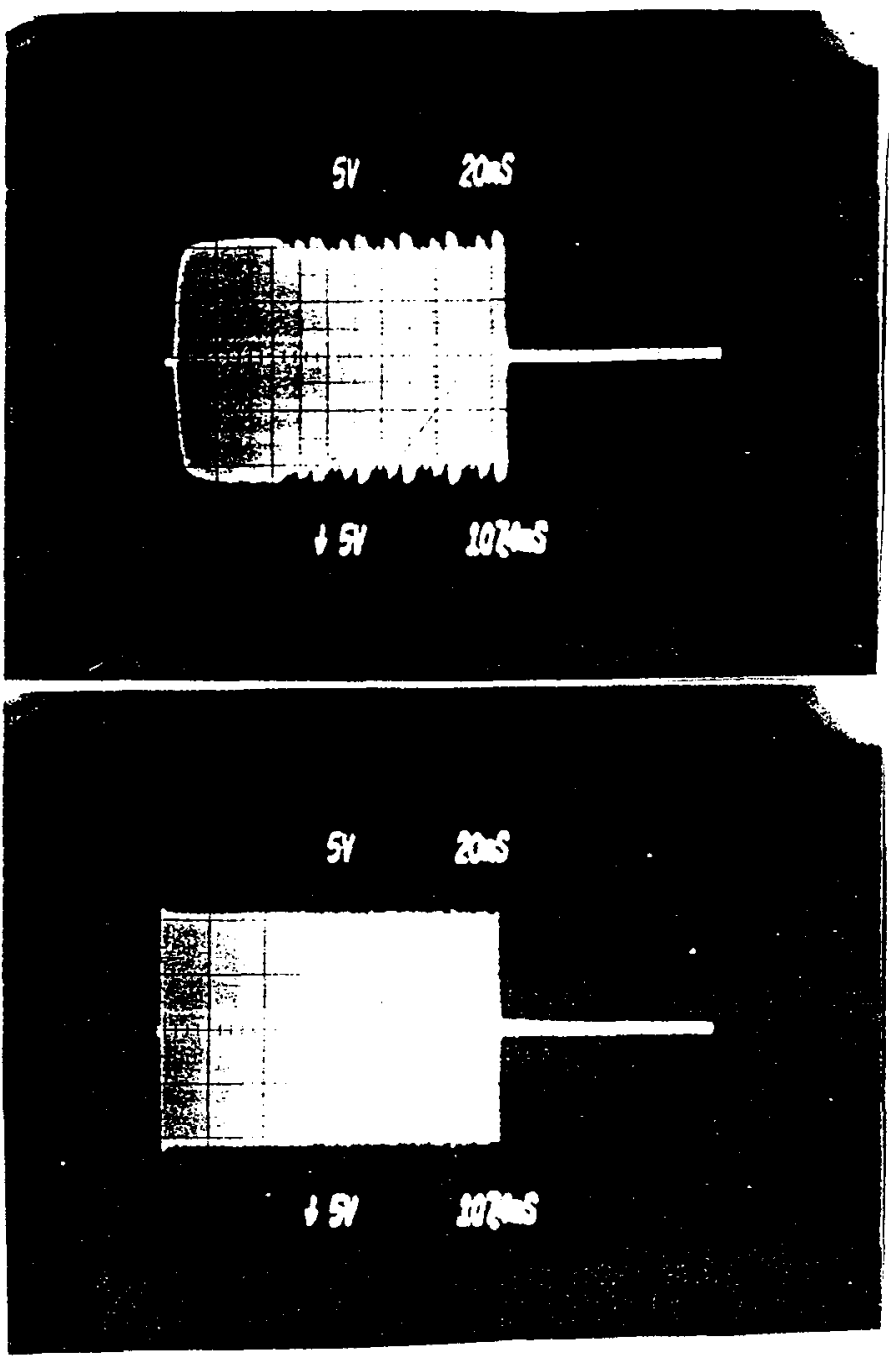

Fig. A-2(B)

AGC Loop Open $V \geq 12 \mathrm{KV}$

Fig. A-2(C) AGC Loop Closed $\mathrm{V}=12 \mathrm{KV}$

Fig. A-2 Oscillograms Depicting the Q-Loss Phenomena

$$
\begin{aligned}
& \mathrm{F}=4.5 \mathrm{MH}: \mathrm{z} \\
& \mathrm{C}=700 \mu \mu \mathrm{F} / \mathrm{Gap} \\
& \text { Probe }=1000: 1
\end{aligned}
$$

